\title{
Duração de sílabas em fronteira de frase fonológica na produção de sentenças sintaticamente ambíguas do português brasileiro
}

\section{Syllable duration in phonological phrase boudaries in the production of syntactically ambiguous sentences in Brazilian Portuguese}

\author{
Melanie Campilongo Angelo \\ Universidade de São Paulo, São Paulo, São Paulo / Brasil \\ melanie.angelo@usp.br \\ Raquel Santana Santos \\ Universidade de São Paulo, São Paulo, São Paulo / Brasil \\ raquelss@usp.br
}

Resumo: Este artigo investiga a duração de sílabas na produção de sentenças ambíguas do tipo SN1-V-SN2-Atributo no português brasileiro, tais como ' $\mathrm{O}$ pai visitou o filho feliz'. Fonologicamente, as diferentes leituras são explicadas pelo fato de o atributo poder ou não se juntar ao SN2 na construção do domínio da frase fonológica (NESPOR; VOGEL, 1996). Angelo e Santos (2015) testaram essas sentenças e encontraram apenas um direcionamento de comportamento, mas não uma diferença significativa nos resultados a depender da duração. No entanto, a quantidade de dados e seu balanceamento afetavam os resultados. Aqui, aplicamos o experimento a mais informantes e balanceamos as estruturas para fins de comparação. Os resultados encontrados revelaram diferenças significativas observando o tipo de estrutura - os falantes alongaram as sentenças com interpretação não local. Os resultados chamam a atenção ainda para dois tipos de estruturas que podem interferir no processo de 
alongamento, impedindo-o: sentenças em que o atributo é formado por adjetivos deverbais e sentenças que possibilitam construções de small clause.

Palavras-chave: aposição local; aposição não local; fronteira prosódica; adjetivos deverbais.

Abstract: This article discusses the production of syllable duration in Brazilian Portuguese as a prosodic cue in ambiguous sentences with a NP1-V-NP2-attribute structure (e.g. 'The father visited his son happy'). Phonologically, the two different interpretations can be explained by the fact that attributes may or may not join NP2 in the construction of the phonological phrase domain (NESPOR; VOGEL, 1996). Angelo and Santos (2015) tested these sentences and found only a bias toward a lengthening when the interpretation is non-local (the father is happy). However, their study lacks a reasonable quantity of data and balance of structures. Here, we rerun the experiment controlling the mentioned problems. Overall results showed significant differences for type of syntactic structure - speakers produced high attachment sentences longer than low attachment ones. The findings signal also to two kinds of structures that may interfere in the process, blocking the lengthening: sentences which the attribute is formed by a non-verbal adjective and sentences which allow small clause constructions.

Keywords: low Attachment; high attachment; prosodic boundary; deverbal adjective.

Recebido em 29 de julho de 2017

Aceito em 14 de setembro de 2017

\section{Introdução}

Esta pesquisa parte do estudo de Angelo e Santos (2015) sobre o uso da pista prosódica de duração de sílabas na produção de sentenças sintaticamente ambíguas do português brasileiro (doravante PB) e busca explicações para os resultados encontrados.

Magalhães e Maia (2006) avaliaram a interpretação da leitura de sentenças que apresentam ambiguidade entre as posições local/não local 
do atributo, ${ }^{1}$ em sentenças como em (1), que podem ter as leituras com aposição não local (a) e com aposição local (b):

(1) A menina venerou a santa sorridente.

a. A menina estava sorridente.

b. A santa estava sorridente.

Angelo e Santos $(2012,2015)$ reformularam os testes aplicados por Magalhães e Maia (2006) para observar o que acontecia com a duração no trecho onde pode haver uma reestruturação prosódica. Segundo Nespor e Vogel (1986), a interface Fonologia-Sintaxe se dá na construção da frase fonológica. Segundo o algoritmo de construção do domínio de frase fonológica, um constituinte de frase fonológica é formado por um núcleo lexical e pode ser reestruturado com seu complemento. Desse modo, as leituras em (1a) vs. (1b) podem ser explicadas pelo fato de o atributo poder ou não se juntar ao SN2 na construção do domínio da frase fonológica, como exemplificado em (2) e (3):

(2) A menina venerou [a santa $\phi][$ sorridente $\phi] \quad>\quad$ a menina venerou [a santa sorridente $\phi$ ]

- A santa estava sorridente ('sorridente' é complemento de 'santa').

(3) A menina venerou [a santa $\phi]$ [sorridente $\phi]>>$ *a menina venerou [a santa sorridente $\phi$ ]

- A menina estava sorridente ('sorridente' não é complemento de 'santa', por isso, não pode se reestruturar e compor apenas uma frase fonológica).

Além do mais, sabe-se que sílabas tônicas e sílabas finais de palavras são alongadas no final de domínios prosódicos (FOUGERON; KEATING, 1997). Se quanto mais próximo das fronteiras, maior a duração das sílabas (CHO; KEATING, 2001; KEATING et al., 2003), deveria acontecer uma variação na duração das sílabas de 'santa' apenas na aposição não local, seja na tônica 'san' ou na átona 'ta', por serem próximas à fronteira nessa interpretação. Ou seja, deveria ocorrer

${ }^{1}$ Este trabalho será apresentado com mais detalhes na seção 3. 
um alongamento nas sílabas do objeto, pois é ele que se encontra em diferentes domínios prosódicos conforme a interpretação escolhida. Um alongamento nas primeiras sílabas do atributo na interpretação não local como, no caso, a sílaba 'so' em 'sorridente', também se justificaria por estar próximo à fronteira. Já na leitura com aposição local, essas sílabas não estariam no final/começo de domínio e, portanto, deveriam ser mais curtas do que com a leitura não local, quando estão no começo/final do domínio.

Como em Magalhães e Maia essas medições não foram feitas, Angelo e Santos $(2012,2015)$ verificaram se havia alguma variação nesse contexto e o que se concluiu foi que não há distinção de duração significativa entre as leituras, embora, sempre que tenha havido um alongamento relevante, ele tenha ocorrido em direção do esperado, ou seja, quando havia uma fronteira prosódica e a leitura de aposição não local. As autoras concluem seu artigo sugerindo que saber esse alongamento possa ser opcional - o que, para ser respondido, precisa de um maior volume de dados. Além disso, esse trabalho fornece poucos dados e não apresenta uma comparação entre diferentes interpretações das sentenças por um mesmo falante. Por fim, nele se analisam conjuntamente estruturas sintáticas locais diferentes (estruturas atributivas e predicativas - cf. seção 1.1).

O objetivo deste artigo é, assim, discutir o que acontece com as sílabas dentro versus às margens de domínios prosódicos em tais sentenças pois, uma vez que há diferentes mapeamentos estruturais a depender da interpretação (aliado ao fato de haver na literatura trabalhos que concluam que sílabas em início e/ou final de domínios prosódicos são mais longas e melhor articuladas), espera-se que, quando o objeto e o atributo não puderem se reestruturar, a duração das sílabas que beiram a fronteira seja maior. Buscamos também responder à questão suscitada pelas autoras sobre a opcionalidade desse processo. Para tanto, reaplicamos o experimento de produção de Angelo e Santos (2012, 2015), com alguns novos cuidados metodológicos, visando buscar evidências da existência ou não do processo de alongamento em fronteiras de frases fonológicas de sentenças ambíguas do PB.

Este artigo está organizado da seguinte maneira: na primeira seção, trazemos os aspectos da descrição sintática, prosódica e fonética necessários para a descrição destas sentenças ambíguas. Na segunda seção, retomamos os estudos sobre desambiguização de sentenças 
ambíguas no português. A terceira seção apresenta a descrição dos objetivos, hipóteses e predições e metodologia quanto ao experimento conduzido. A quarta seção traz os resultados encontrados. Na quinta e sexta seções, faz-se uma discussão dos resultados e, por fim, na sétima seção, apresentamos as considerações finais.

\section{A estrutura de sentenças do tipo SN1- Verbo - SN2 - Atributo}

\subsection{Perspectiva sintática}

De acordo com Mioto (2004), de um modo geral, as construções sintáticas se dão por meio de um núcleo $\mathrm{X}$ que rege diretamente seu complemento e que é comandado pelo seu especificador. Partindo dessa descrição, podemos distinguir as sentenças do tipo SN1-Verbo-SN2Atributo em duas estruturas: uma com o atributo modificando o sujeito e outra com o atributo modificando o objeto (cf. Estruturas 4 e 5 a seguir): ${ }^{2}$

(4) $\left[\left[[\mathrm{O} \text { aluno }]_{\mathrm{DP}}\left[[\text { consult- }]_{\mathrm{V}}[\text { o monitor }]_{\mathrm{DP}}\right]_{\mathrm{V}},\right]_{\mathrm{VP}}[\text { cismado }]_{\mathrm{AP}}\right]_{\mathrm{VP}}$.

(5) $\left[\left[[\text { O aluno }]_{\mathrm{DP}}\left[[\text { consult- }]_{\mathrm{V}}\left[\left[[\mathrm{o}]_{\mathrm{D}}\left[[\text { monitor }]_{\mathrm{N}}\left[[\text { cismado }]_{\mathrm{AP}}\right]_{\mathrm{N}},\right]_{\mathrm{NP}}\right]\right.\right.\right.\right.$ $\left.\left.\left.\left.{ }_{\mathrm{D}},\right]_{\mathrm{DP}}\right]_{\mathrm{V}},\right]_{\mathrm{VP}}\right]_{\mathrm{VP}}$

Como se pode observar, na estrutura em (4), o AP [cismado] pende de VP, enquanto o DP [o monitor] é nó irmão de V [consult-], conduzindo à interpretação de que 'o aluno estava cismado'. Na estrutura de (5), [cismado] é nó irmão de [monitor], compondo ambos o mesmo NP e gerando a interpretação de 'monitor cismado'.

Além disso, há que se considerar que mesmo nessas estruturas há uma diferença entre sentenças como 'A Maria trabalhou magoada' e 'O João considera a Maria bonita'. Segundo Foltran (1999), no primeiro caso, o verbo 'trabalhar' só seleciona um argumento, o de sujeito, no caso [A Maria], o que não exclui a relação evidente entre o AP [magoada] e o DP [A Maria]. No segundo exemplo, o verbo 'considerar' seleciona, além

\footnotetext{
${ }^{2}$ Por questões de espaço e para não fugir do escopo da presente pesquisa, não cabe nesta seção discutir os sintagmas acima do sintagma verbal (VP), e pretende-se com as estruturas apenas ilustrar como se explica na Sintaxe a diferença de significado das sentenças.
} 
do sujeito, o constituinte [a Maria bonita] inteiramente, o que, de acordo com a autora, é uma evidência para classificar [a Maria bonita] como uma pequena oração selecionada pelo verbo, ou seja, uma small clause.

Esses dois tipos de sentença apresentam diferentes estruturas sintáticas. Para Foltran e Mioto (2007), o adjetivo está dentro de um DP nas estruturas de adjunção (sendo adjunto de um sintagma nominal (NP) (cf. (6a)), enquanto que ele é um predicativo de um argumento nas estruturas de small clause. Se o argumento é um DP, o adjetivo não pertence a ele, mas forma com ele a small clause (cf. (6b)):

(6) A mãe encontrou a filha suada.

a. Adjunção: [ ${ }_{D P}$ a filha suada]

b. Small clause: $\left[_{\mathrm{SC}}\right.$ a filha suada $]$
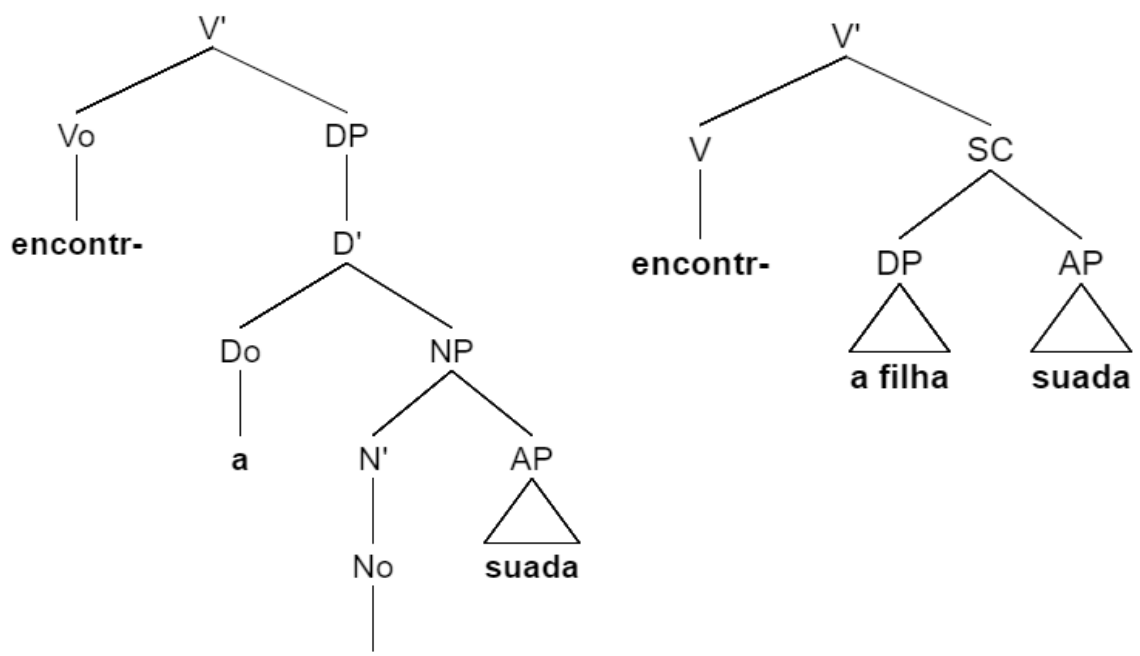

filha

Fonte: Angelo e Santos (2017, p. 1.172)

Tendo esse fato em mente, é necessário um cuidado especial na escolha do verbo ao se trabalhar com ambiguidade entre as aposições não local e local de uma sentença. Verbos como 'visitar', 'ajudar', 'consultar' selecionam entidades: visitar [o filho feliz] / ajudar [a mãe carinhosa] (estruturas adjuntivas), ao passo que outros verbos, como 'comprar', 'encontrar', 'considerar', 'julgar', entre outros, têm a possibilidade de 
selecionar uma situação, um estado de coisas: comprar [o carro quebrado] / considerar [o réu inocente] (small clauses, estruturas predicativas). A diferença sintática acaba trazendo consequências para a estrutura prosódica, já que, como veremos, estruturas locais por small clause apresentam a mesma estrutura prosódica que leituras apositivas não locais.

\subsection{Perspectiva prosódica}

Assumimos, neste artigo, a proposta de Nespor e Vogel (1986), para quem há 7 níveis prosódicos: sílaba, pé, palavra fonológica, grupo clítico, frase fonológica, sentença e frase entoacional. Os níveis da palavra prosódica e acima são construídos levando-se em conta informações de outros componentes gramaticais (morfologia, sintaxe, semântica), o que significa que a fonologia de uma frase não diz respeito apenas à concatenação das sequências fonológicas das palavras. No caso das sentenças ambíguas, por exemplo, há um mesmo conjunto de palavras, mas que subjacentemente se organizam em estruturas sintáticas diferentes e, consequentemente, em diferentes estruturas prosódicas.

De acordo com Nespor e Vogel (1986), a estrutura prosódica é independente, mas gerada levando-se em conta informações provenientes da sintaxe: as informações sintáticas são mapeadas no nível da frase fonológica $(\phi)$ por meio das regras de mapeamento apresentadas em (7) - (NESPOR; VOGEL, 1986, p.168-173):

(7) Phonological Phrase formation:

I. domain:

The domain of $\Phi$ consists of a clitic group (C) which contains a lexical head $(\mathrm{X})$ and all $\mathrm{Cs}$ on its nonrecursive side up to the $\mathrm{C}$ that contains another head outside of the maximal projection of $\mathrm{X}$.

II. construction:

Join into an n-ary branching $\Phi$ all Cs included in a string delimited by the definition of the domain of $\Phi$.

$\Phi$ Restructuring (optional):

A nonbranching $\Phi$ which is the first complement of $\mathrm{X}$ on its recursive side is joined into the $\Phi$ that contains $\mathrm{X}$. 
De acordo com o algoritmo apresentado em (7), uma palavra lexical juntamente com seus clíticos forma o grupo clítico (C) (e.g. 'o filho', 'cismado'). Um adjetivo, além de compor ele mesmo uma frase fonológica, pode ser incorporado ao domínio que contém a palavra que ele modifica em um processo de reestruturação: anexar a uma frase fonológica o primeiro complemento de X que esteja em seu lado recursivo, ou seja, o lado em que se encontram os complementos do núcleo lexical (e.g. 'o filho cismado') (NESPOR; VOGEL, 1986, p.173). ${ }^{3}{ }^{4}$ Essa reestruturação só pode ocorrer se o complemento for composto de uma só palavra (logo, não é possível que as frases fonológicas 'o filho' e 'muito cismado' sejam reestruturados em 'o filho muito cismado').

Esse mapeamento reflete diferenças estruturais de sentenças ambíguas de adjunção, como em (8). A princípio, na interpretação de que o monitor está cismado, 'cismado' é complemento de 'monitor', formado por um único grupo clítico, e, portanto, as duas frases fonológicas podem ser reestruturadas (8b); na interpretação de que o aluno está cismado, não há relação entre 'monitor' e 'cismado'; portanto, a reestruturação não é possível entre as frases fonológicas (8a):

(8) O aluno consultou o monitor cismado.

a. leitura: $\mathrm{O}$ aluno cismado.

[o aluno ${ }_{\phi}$ ] [consultou ${ }_{\Phi}$ ] [o monitor ${ }_{\phi}$ ] [cismado ${ }_{\phi}$ ] $>>*\left[\right.$ aluno $\left._{\phi}\right]\left[\right.$ consultou $\left._{\phi}\right]\left[0\right.$ monitor cismado $\left.{ }_{\phi}\right]$ $>\quad\left[\right.$ o aluno $\left._{\phi}\right]\left[\right.$ consultou o monitor $\left.{ }_{\Phi}\right]\left[\right.$ cismado $\left._{\Phi}\right]$

\footnotetext{
${ }^{3}$ As autoras também propõem que a reestruturação é específica da língua, ou seja, há línguas que não possibilitam a reestruturação, há línguas que obrigatoriamente exigem a reestruturação nos casos possíveis, enquanto que há línguas em que a reestruturação é possível, mas opcional. Estudos como os de Abousalh (1997), Santos (2003), Sândalo e Truckenbrodt (2002) sobre o português brasileiro defendem que nessa língua a reestruturação é possível; no entanto, eles não discutem se é uma reestruturação opcional ou obrigatória, dado que o fenômeno que eles analisam é opcional (o stress shift).

${ }^{4}$ Enfatizamos, porém, que a proposta de Nespor e Vogel é de 1986, quando não havia distinção na Teoria X-Barra entre complemento e adjunto e, da mesma forma, NP era a projeção lexical máxima em vez de DP. Hoje, há trabalhos que mostram que adjuntos funcionam como complementos (cf. SANTOS, 2003, que demonstra a retração acentual acontece entre o verbo e o adjunto). Existem diversos trabalhos que reveem Nespor e Vogel (e.g. GUIMARÃES, 1997; FROTA, 2000; VIGÁRIO, 2003).
} 
b. leitura: O monitor cismado.

$\left[\right.$ o aluno $\left.{ }_{\Phi}\right]\left[\right.$ consultou $\left._{\Phi}\right]\left[\right.$ monitor $\left._{\Phi}\right]\left[\right.$ cismado $\left._{\Phi}\right]$ $>\left[\right.$ o aluno $\left._{\Phi}\right]\left[\right.$ consultou $\left.{ }_{\Phi}\right]\left[\right.$ o monitor cismado $\left.{ }_{\Phi}\right]$

Até onde sabemos, Angelo e Santos (2015) foi o primeiro trabalho sobre a estrutura prosódica de small clauses no português brasileiro. Aplicando estritamente a proposta de Nespor e Vogel, a reestruturação das frases fonológicas entre o adjetivo e o nome não pode ocorrer porque, embora a interpretação seja local, o adjetivo não está inserido na projeção máxima do nome (cf. (6) acima e o algoritmo em (7)). O resultado é que essas estruturas são mapeadas com uma fronteira entre o núcleo e o complemento - cf. (9).

(9) $\left[\mathrm{O}\right.$ josé $\left._{\Phi}\right]\left[\right.$ encontrou $\left._{\Phi}\right]\left[\right.$ o carro $\left._{\Phi}\right]\left[\right.$ quebrado $\left._{\Phi}\right]$

Observe-se, então, que a estrutura prosódica das sentenças por small clause, embora tenha leitura local, é igual a estrutura prosódica das sentenças com leitura não local.

\subsection{Perspectiva fonética}

Trabalhos sobre a fonética dos segmentos em fronteiras prosódicas nas mais diversas línguas mostram que contrastes fonêmicos são maximizados/ mais bem realizados no começo dos domínios prosódicos (cf. CHO; KEATING, 2001; KEATING et al., 2003). Interessantemente, esses efeitos variam conforme os níveis prosódicos em que aparecem. Esses estudos comprovaram que os contrastes foram maximizados e o alongamento aumentava à medida que os domínios prosódicos ficavam mais altos. Ou seja, um alongamento em fronteira de frase fonológica é menor do que um alongamento em fronteira de sentença, mas maior do que aquele em grupo clítico, por exemplo. O efeito do alongamento foi encontrado tanto na fronteira inicial (BYRD; SALTZMAN,1998; CHO; KEATING, 2001; CHO, 2006; FOUGERON, 2001; KEATING et al., 2003; TABAIN, 2003), quanto na final (BYRD, 2000; BYRD; SALTZMAN, 1998; CHO, 2006; TABAIN, 2003; TABAIN; PERRIER, 2005) dos domínios prosódicos.

Santos e Leal (2008) investigaram se os mesmos efeitos são encontrados em PB por meio de um experimento com palavras inseridas em 
fronteiras de diferentes domínios prosódicos em sentenças não ambíguas. Tanto na fronteira esquerda quanto na direita dos domínios prosódicos, só houve diferença significativa (com maior duração) na fronteira de frase entoacional. Assim, em PB, não haveria como distinguir pela duração se há fronteira, por exemplo, de frase fonológica, em uma sentença. As autoras, no entanto, sugerem que pode ser o caso de o PB fazer uso do alongamento quando para desambiguizar sentenças ambíguas como (8).

\section{Estudos anteriores em PB}

Inúmeros trabalhos discutem o papel da prosódia na interpretação de sentenças sintaticamente ambíguas (cf. GRAVINA; SRVARTMAN, 2013; PIERREHUMBERT, 1980; LADD, 1996; MAIA, 2011; LOURENÇO; MAIA; MORAES, 2004; FODOR, 2002; FONSECA, 2008; FRAZIER, 1979). No entanto, o foco desses trabalhos está mais no processamento do que na explicação do fato de a estrutura prosódica poder ser diferente nas distintas interpretações. Magalhães e Maia (2006), por exemplo, procuram por padrões de desambiguação de estruturas prosódicas por aposição de atributo. Aos autores interessava descobrir se há uma preferência por algum tipo de aposição quando algumas segmentações prosódicas são inseridas nas orações, o que indicaria uma prosódia implícita guiando a interpretação de sentenças não marcadas. Os resultados mostraram que há uma preferência para a interpretação como aposição local. Em sentenças do tipo SN1-V-SN2-Atributo, os autores mediram o final do atributo. Os resultados indicaram uma duração maior quando a aposição é não local, mas, interessantemente, esse resultado não é previsto pela estruturação prosódica, já que, nessa fronteira (fronteira direita do atributo), o domínio prosódico é o mesmo tanto em interpretação local quanto não local (compare o mapeamento prosódico de (8a) vs (8b)). Magalhães e Maia creditam seus resultados a efeitos do Princípio de Aposição Local (com base no princípio de late closure (FRAZIER, 1979) e prosódia implícita (FODOR, 1998). Segundo o princípio de late closure, um sintagma só se fecha quando não há outro elemento que possa ser aposto a ele, e, em ambos os casos, esse elemento é existente, pois o atributo modifica o objeto. Segundo o princípio de prosódia implícita, em sentenças simples, sem modificações prosódicas, os falantes preferem intepretações locais a não locais. Em outras palavras, as interpretações locais seriam default e só seriam encontradas variações prosódicas no caso de interpretações não locais. 
Angelo e Santos $(2012,2015)$, com base nos resultados de Magalhães e Maia (2006) e Santos e Leal (2008), investigaram se em sentenças ambíguas haveria uma distinção prosódica (do ponto de vista da duração das sílabas em fronteiras de frases fonológicas) entre as interpretações de sentenças ambíguas por aposição de atributo. Para fins metodológicos, as autoras adaptaram nove sentenças do experimento de Magalhães e Maia (2006) de forma a facilitar a medida de duração, substituindo, por exemplo, os segmentos oclusivos para fricativos (que tinham seu início mais fácil de detectar acusticamente. As nove sentenças foram selecionadas e inseridas em histórias que direcionavam a determinada interpretação. Trinta informantes nascidos em São Paulo, adultos e de nível universitário, foram escolhidos e divididos em dois grupos. Um grupo leu as histórias com uma interpretação, ao passo que o outro grupo leu as histórias com a segunda interpretação (ambos apresentavam leituras dos dois tipos, ou seja, direcionando à aposição não local e à aposição local). As leituras foram feitas, primeiramente, em silêncio, para que a interpretação desejada fosse garantida e, em seguida, em voz alta, quando gravadas. Tendo como hipótese uma relação entre o alongamento e a estrutura prosódica, a predição era de que haveria alguma distinção entre as leituras e de que as leituras do tipo não local apresentariam algum alongamento das sílabas realizado pelo falante se comparadas às mesmas sentenças na leitura local (fosse esse alongamento na sílaba anterior ou posterior do local de reestruturação da frase fonológica ou, até mesmo, na pausa). Sendo assim, em uma frase como em (10), o trecho medido foi de 'lho' até 'fe'.

\section{(10) O pai visitou o fiLHO FEliz.}

Os resultados encontrados não confirmaram as hipóteses das autoras, mas observou-se uma tendência: os informantes que diferenciaram as durações sempre o fizeram em favor de uma maior duração das sentenças em aposição não local. Quando se comparavam apenas as estruturas (local vs. Não local), as sentenças com reestruturação foram sempre mais longas, mostrando certa tendência do falante em realizar esse alongamento, embora também não tenha sido uma diferença estatisticamente significativa. Porém, não houve diferença na duração entre fronteira de frase fonológica (que indicava aposição não local) e grupos clíticos (o domínio imediatamente inferior, quando não há fronteira de frase fonológica). 
O trabalho de Angelo e Santos, no entanto, não possibilita comparar as diferentes versões de cada sentença lidas por um mesmo informante, o que pode ser um problema, pois cada informante tem seu ritmo e velocidade de leitura. Ao mesmo tempo, esse trabalho também não controlou separadamente a distinção da aposição local por adjunto ou predicativa. Pela quantidade de dados, também não possibilita discutir a opcionalidade do processo. Finalmente, nesse estudo e nos que the serviram de base, sentenças apositivas por adjunto e sentenças apositivas por small clause foram analisadas conjuntamente. Se o alongamento obedece a fronteiras prosódicas, o resultado não significativo pode ter sido causado por essas duas estruturas terem sido analisadas conjuntamente.

\subsection{0 experimento}

Para investigar o uso do alongamento no $\mathrm{PB}$ em fronteiras prosódicas de sentenças ambíguas como forma de desambiguação, um experimento com falantes brasileiros produzindo sentenças-alvo ambíguas torna possível verificar a existência do processo na língua. ${ }^{5}$

Replicamos os experimentos de Angelo e Santos (2012, 2015) da seguinte maneira: recuperamos informantes e pedimos a eles que lessem a versão oposta das sentenças de Angelo e Santos. Em seguida, gravamos informantes novos, que leram as duas versões das sentenças. Isso gerou um corpus mais robusto. Somente após o experimento rodado foi que se percebeu a possibilidade de diferença estrutural nas sentenças de aposição local. Assim, analisamos os resultados encontrados levando em conta essas diferenças sintáticas das sentenças.

\subsection{Objetivos, hipóteses e predições}

Partindo da hipótese de que há uma interação entre fonologia e sintaxe que se concretiza em pistas fonológicas para o falante, as quais servem para desambiguizar as sentenças ambíguas, nosso objetivo é observar se o falante direciona a produção de sentenças ambíguas (lidas dentro de um contexto de desambiguação) por meio de diferenças na duração do trecho em que pode haver reestruturação Nossa hipótese leva às seguintes predições quanto ao nosso experimento:

\footnotetext{
${ }^{5}$ Aprovação do Comitê de Ética para pesquisas com seres humanos deferida pelo Instituto de Psicologia da Universidade de São Paulo e registrada por meio do CAAE: 45791815.5.0000.5561.
} 
i. Dados os resultados de Angelo e Santos (2012, 2015), ocorrerá ao menos uma tendência à produção de alongamento para as sentenças de aposição não local em comparação às sentenças de aposição local (hipótese nula: sentenças com aposição não local e local terão a mesma duração no trecho medido);

ii. Dados os resultados de Angelo e Santos (2012, 2015), espera-se que a realização do alongamento seja um processo opcional dos falantes para marcar a interpretação não local (hipótese nula: $\mathrm{O}$ alongamento vai ocorrer em toda produção não local para todos os falantes);

Além disso, esperamos observar os efeitos de duração em estruturas em que small clauses são possíveis. Nenhuma previsão a esse respeito é elencada, já que as sentenças que podem ser sentenças por small clause também podem ser sentenças por adjunção.

\section{Metodologia}

As sentenças analisadas no experimento foram as mesmas de Angelo e Santos (2015), baseadas nas sentenças de Magalhães e Maia (2006) - cf. Quadro 1.

QUADRO 1 - Sentenças analisadas e interpretações

\begin{tabular}{|l|l|}
\hline \multicolumn{1}{|c|}{ Sentenças } & Interpretações possíveis \\
\hline S1. O pai visitou o filho feliz. & A, B \\
\hline S2. A babá ninou a menina chorando. & A, B \\
\hline S3. O aluno consultou o monitor cismado. & A, B \\
\hline S4. O sobrinho cumprimentou o tio sonolento. & A, B \\
\hline S5. O assessor auxiliou o presidente furioso. & A, B \\
\hline S6. O repórter entrevistou o político sozinho. & A, B \\
\hline S7. A mãe procurou a filha magoada. & A, B \\
\hline S8. A mãe encontrou a filha suada. & A, C \\
\hline S9. O réu encontrou o advogado nervoso. & A, C \\
\hline
\end{tabular}

Fonte: Elaborado pelas autoras. 
Todas as sentenças possibilitavam interpretações não locais (A) e locais. A interpretação local pode ser feita de duas formas: algumas sentenças favoreciam apenas a adjunção do atributo ao verbo (sentenças 1 a 7, identificadas como interpretação (B)), enquanto que outras possibilitavam para as locais, além da adjunção, a estrutura de small clause (sentenças 8 e 9, identificadas como interpretação (C)). ${ }^{6}$

As sentenças foram inseridas no final de histórias que as desambiguizavam, dando margem apenas a uma interpretação, quer de aposição não local (versão A), quer de aposição local (versão B ou C), totalizando 18 histórias. As 18 histórias foram agrupadas em duas listas, que continham, cada uma, apenas uma ou outra versão de cada sentença, mais 6 histórias distratoras.

Participaram do teste 30 falantes adultos, com nível universitário, nascidos e moradores de São Paulo. Os 30 informantes leram as duas listas em momentos diferentes (sendo que 10 deles, informantes de Angelo e Santos (2015), leram apenas a lista que não haviam lido no experimento das autoras). Em suma, o corpus é composto de 540 dados de produção (9 sentenças x 2 interpretações x 30 informantes).

As histórias foram integralmente gravadas utilizando-se o programa Audacity 1.3. Beta Unicode. Posteriormente, por meio do software Praat, foram recortadas apenas as sentenças ambíguas e medidas a duração, em milissegundos, desde a sílaba final do objeto até a sílaba inicial do atributo (por exemplo, em 'filho feliz', o trecho medido foi tho $f e$ ). Dessa forma, captura-se qualquer diferença que o falante possa estar fazendo na sílaba final de SN2, na sílaba inicial do Atributo, ou mesmo uma maior duração de pausa entre esses dois argumentos. Todos esses eventos fonéticos podem ser reflexos de uma fronteira de frase fonológica entre SN2 e Atributo, resultante de uma estrutura com aposição não local.

\section{Resultados}

Os resultados foram analisados quanto à estrutura sintática, informante e sentença. A análise estatística foi com o programa R. Os

\footnotetext{
${ }^{6}$ Como a detecção desse tipo de estrutura por small clause só foi percebida após o teste ter sido rodado, não há um equilíbrio quantitativo entre sentenças com verbos atributivos (adjunção) e sentenças com possibilidade de leitura atributiva ou predicativa. (small clause).
} 
testes estatísticos utilizados para a produção foram o Teste (paramétrico) T de Student para amostras pareadas (dependentes) - utilizado quando se pretende comparar medidas repetidas do mesmo falante (médias) -, e o teste de Wilcoxon (não-paramétrico) para amostras pareadas (medianas). Os dados são analisados por estrutura, por sentença e por informante.

\subsection{Por estrutura de aposição}

A Tabela 1 discrimina os valores dos testes estatísticos para a aplicação por tipo de estrutura. Na primeira linha, um geral das nove sentenças (comparação A vs. B/C) é pautado. As estruturas de A em comparação com as B representam as sete sentenças que não possibilitam small clause. Por fim, a comparação de A com C, na última linha, é apenas para as duas sentenças que possibilitam small clause.

TABELA 1 - Comparação da média e mediana de duração da leitura (em milissegundos) conforme a estrutura, para os 30 falantes

\begin{tabular}{c|c|c|c|c}
\hline \multirow{2}{*}{ Estrutura } & \multicolumn{2}{|c|}{ Teste t } & \multicolumn{2}{c}{ Teste de Wilcoxon } \\
\cline { 2 - 5 } & $\begin{array}{c}\text { Média das diferenças } \\
\text { entre as médias } \\
(\mathbf{I C 9 5 \% )}\end{array}$ & $\mathbf{p}$-valor & $\begin{array}{c}\text { Pseudo-mediana } \\
\text { das diferenças entre } \\
\text { medianas (IC95\%) }\end{array}$ & p-valor \\
\hline $\boldsymbol{A}$ & 21,13 & $<\mathbf{0 , 0 0 1}$ & $\begin{array}{c}16,26 \\
(12,09 ; 20,81)\end{array}$ & $<\mathbf{0 , 0 0 1}$ \\
$\boldsymbol{B} / \boldsymbol{C}$ & $(13,82 ; 28,45)$ & & 17,79 & $<\mathbf{0 , 0 0 1}$ \\
\hline $\boldsymbol{A}$ & 21,98 & $<\mathbf{0 , 0 0 1}$ & $(12,99 ; 23,00)$ & \\
$\boldsymbol{B}$ & $(13,92 ; 30,03)$ & & 10,79 & $\mathbf{0 , 0 1 9}$ \\
\hline $\boldsymbol{A}$ & 18,18 & $\mathbf{0 , 0 4 2}$ & $(2,04 ; 21,31)$ & \\
\hline $\boldsymbol{C}$ & $(0,72 ; 35.63)$ & & & \\
\hline
\end{tabular}

Fonte: Angelo (2016, p. 79)

O Teste $t$ para amostras pareadas compara as médias de duração das estruturas de $\mathrm{A} \mathrm{e} \mathrm{B}$ ( ou A e C) que foram medidas nos mesmos falantes. Foi aplicado, também, um teste não paramétrico devido à assimetria da distribuição dos tempos de duração. ${ }^{7} \mathrm{O}$ teste não paramétrico é baseado na comparação das medianas e, assim como no caso das médias, assinala

7 O Teste $t$ tem pressupostos que precisam ser atendidos para que seu resultado seja fidedigno, como dados provenientes de distribuição normal, que é simétrica. 
para diferenças entre as estruturas, com maior mediana para a estrutura de A em ambas as comparações. É interessante notar que, nos dois testes, os resultados foram similares: podemos afirmar que as médias das estruturas não local e local são estatisticamente distintas, com a média das não locais (A) superior em todas as comparações de ambos os testes. ${ }^{8}$ Porém, apesar de o valor da comparação de A e C (p-valor de 0,042 (média) e 0,019 (mediana)) ser significativo, não foi tão baixo como na comparação geral (A vs. B/C) e na específica de $\mathrm{A} v s . \mathrm{B}$, o que pode indicar não só a necessidade dessas estruturas serem olhadas mais cuidadosamente, como também uma variação de resultado por se tratar de apenas duas sentenças.

\subsection{Por sentenças}

A segunda comparação considerou cada sentença contrapondo as leituras A (aposição não local) versus as leituras B ou C (aposição local, sendo B apenas adjunção, e C, ambíguo entre adjunção e small clause), desconsiderando os falantes. Os valores estatísticos estão dispostos na Tabela 2 a seguir.

Os valores da Tabela não respondem diretamente qual estrutura foi mais longa que a outra, mas sim se há significância entre a diferença das durações. Por isso, a média/mediana de $\mathrm{B}$ ou $\mathrm{C}$ foi subtraída da média / mediana de A. Assim, valores positivos na coluna de IC95\% mostram que as produções com leitura não local (A) foram mais longas; semelhantemente, valores negativos indicam que $\mathrm{B}$ ou $\mathrm{C}$ foram mais longas. Para cada valor significativo, deve-se olhar para o IC95\% em busca de saber qual das estruturas foi alongada.

\footnotetext{
${ }^{8}$ Isso pode ser verificado pelos valores positivos (maiores que zero) dos valores IC95\%, pois, para calcular as médias/medianas, subtraiu-se de $\mathrm{A}$ os valores de B/C.
} 
TABELA 2 - Comparação da média e mediana da duração (em milissegundos) conforme a sentença e suas estruturas, para os 30 falantes

\begin{tabular}{|c|c|c|c|c|c|}
\hline \multirow[b]{2}{*}{ Sentença } & \multirow[b]{2}{*}{ Estruturas } & \multicolumn{2}{|l|}{ Teste $t$} & \multicolumn{2}{|c|}{ Teste de Wilcoxon } \\
\hline & & $\begin{array}{l}\text { Média das diferenças } \\
\text { entre as médias } \\
\text { (IC95\%) }\end{array}$ & p-valor & $\begin{array}{c}\text { Pseudo-mediana } \\
\text { das diferenças entre } \\
\text { medianas (IC95\%) }\end{array}$ & p-valor \\
\hline S1 & $\begin{array}{l}\text { A } \\
\text { B }\end{array}$ & $\begin{array}{c}39,97 \\
(18,28 ; 61,66)\end{array}$ & $<0,001$ & $\begin{array}{c}32,05 \\
(14,26 ; 60,28)\end{array}$ & $<0,001$ \\
\hline$S 2$ & $\begin{array}{l}\text { A } \\
\text { B }\end{array}$ & $\begin{array}{c}19,73 \\
(-4,93 ; 44,39)\end{array}$ & 0,113 & $\begin{array}{c}12,22 \\
(-0,88 ; 26,49)\end{array}$ & 0,064 \\
\hline$S 3$ & $\begin{array}{l}\text { A } \\
\text { B }\end{array}$ & $\begin{array}{c}7,44 \\
(-31,63 ; 46,51)\end{array}$ & 0,700 & $\begin{array}{c}-0,035 \\
(-18,10 ; 18,49)\end{array}$ & 0,984 \\
\hline$S 4$ & $\begin{array}{l}\text { A } \\
\text { B }\end{array}$ & $\begin{array}{c}20,67 \\
(9,97 ; 31,37)\end{array}$ & $<0,001$ & $\begin{array}{c}19,49 \\
(8,32 ; 32,17)\end{array}$ & 0,001 \\
\hline$S 5$ & $\begin{array}{l}\text { A } \\
\text { B }\end{array}$ & $\begin{array}{c}29,64 \\
(13,28 ; 46,00)\end{array}$ & $<0,001$ & $\begin{array}{c}26,31 \\
(12,60 ; 42,90)\end{array}$ & $<0,001$ \\
\hline S6 & $\begin{array}{l}\text { A } \\
\text { B }\end{array}$ & $\begin{array}{c}21,00 \\
(7,09 ; 34,89) \\
\end{array}$ & 0,004 & $\begin{array}{c}20,26 \\
(9,14 ; 31,94)\end{array}$ & 0,001 \\
\hline$S 7$ & $\begin{array}{l}\text { A } \\
\text { B }\end{array}$ & $\begin{array}{c}15,41 \\
(-0,42 ; 31,24)\end{array}$ & 0,056 & $\begin{array}{c}14,60 \\
(5,53 ; 26,66)\end{array}$ & 0,008 \\
\hline 58 & $\begin{array}{l}\mathbf{A} \\
\mathbf{C}\end{array}$ & $\begin{array}{c}-3,62 \\
(-23,71 ; 16,46)\end{array}$ & 0,715 & $\begin{array}{c}0,71 \\
(-12,66 ; 13,55) \\
\end{array}$ & 0,952 \\
\hline 59 & $\begin{array}{l}\mathbf{A} \\
\mathbf{C}\end{array}$ & $\begin{array}{c}39,98 \\
(7,67 ; 53,43)\end{array}$ & 0,006 & $\begin{array}{c}22,25 \\
(7,67 ; 53,43)\end{array}$ & 0,001 \\
\hline
\end{tabular}

Fonte: ANGELO (2016, p. 82-83)

Os testes para comparação das médias e medianas mostram que, nas comparações de $\mathrm{A}$ com $\mathrm{B}$, há diferenças significativas da média e mediana das sentenças S1, S4, S5 e S6 e também da mediana da sentença S7. Para a comparação de A e C, apenas a sentença S9 apresentou média e mediana significativas. Todos os valores significativos indicam uma maior duração da estrutura de A (IC95\% > 0). Observando as médias das diferenças entre as médias (Coluna 3) e médias das diferenças entre as medianas (Coluna 5), apenas a mediana da S3 e a média da S8 apresentaram a versão local (B ou C) mais longa que a não local (A), mas essa diferença não foi significativa. Em suma, apenas S2, S3 e S8 não apresentam diferença significativa entre as leituras nem nas médias, nem nas medianas. 


\subsection{Por falantes}

Estatisticamente, buscou-se confirmar que nenhum dos falantes foge dos padrões de leitura. A Tabela 3 traz o valor de significância das diferenças entre as médias de todas sentenças não local (A) versus local (B). Como destacado no início dessa seção de resultados, as sentenças $\mathrm{C}$ foram produzidas mais longas do que as sentenças B (cf. Tabela 3). No entanto, não é possível analisar a variabilidade de sentenças $C$ isoladamente, pois, como a análise aqui conduzida é por falante, há apenas duas medidas desse tipo de interpretação para cada um deles, o que resulta em pouca variabilidade.

TABELA 3 - Comparação da duração (em milissegundos) para cada falante

\begin{tabular}{|c|c|c|c|}
\hline \multicolumn{4}{|c|}{ Teste $^{\text {t } 9}$} \\
\hline Falante & Estrutura & $\begin{array}{l}\text { Média das diferenças entre as médias } \\
\text { (IC95\%) }\end{array}$ & p-valor \\
\hline F5 & $\begin{array}{l}\mathrm{A} \\
\mathrm{B}\end{array}$ & $\begin{array}{c}27,57 \\
(-80,97 ; 136,13) \\
\end{array}$ & 0,5899 \\
\hline F13 & $\begin{array}{l}\text { A } \\
\text { B }\end{array}$ & $\begin{array}{c}28,53 \\
(-85,18 ; 142,25)\end{array}$ & 0,5945 \\
\hline F14 & $\begin{array}{l}\text { A } \\
\text { B }\end{array}$ & $\begin{array}{c}80,99 \\
(-109,17 ; 271,16)\end{array}$ & 0,361 \\
\hline F16 & $\begin{array}{l}\mathrm{A} \\
\mathrm{B}\end{array}$ & $\begin{array}{c}10,93 \\
(-153,95 ; 175,83)\end{array}$ & 0,8874 \\
\hline F17 & $\begin{array}{l}\text { A } \\
\text { B }\end{array}$ & $\begin{array}{c}7,59 \\
(-110,69 ; 125,88)\end{array}$ & 0,8902 \\
\hline F18 & $\begin{array}{l}\text { A } \\
\text { B }\end{array}$ & $\begin{array}{c}106,13 \\
(-90,75 ; 303,02)\end{array}$ & 0,2504 \\
\hline F19 & $\begin{array}{l}\text { A } \\
\text { B }\end{array}$ & $\begin{array}{c}-17,8 \\
(-127,37 ; 91,58)\end{array}$ & 0,7279 \\
\hline F23 & $\begin{array}{l}\text { A } \\
\text { B }\end{array}$ & $\begin{array}{c}16,14 \\
(-80,05 ; 112,32)\end{array}$ & 0,7184 \\
\hline F25 & $\begin{array}{l}\text { A } \\
\text { B }\end{array}$ & $\begin{array}{c}28,55 \\
(-65,25 ; 122,34) \\
\end{array}$ & 0,5198 \\
\hline F27 & $\begin{array}{l}\mathrm{A} \\
\mathrm{B}\end{array}$ & $\begin{array}{c}39,94 \\
(-13,66 ; 93,54)\end{array}$ & 0,1302 \\
\hline F31 & $\begin{array}{l}\text { A } \\
\text { B }\end{array}$ & $\begin{array}{c}19,64 \\
(-33,89 ; 73,17)\end{array}$ & 0,4389 \\
\hline
\end{tabular}

${ }^{9}$ Apenas o Teste $\mathrm{t}$ foi realizado, pois compara medidas repetidas do mesmo indivíduo. 


\begin{tabular}{|c|c|c|c|}
\hline F32 & $\begin{array}{l}\mathrm{A} \\
\mathrm{B}\end{array}$ & $\begin{array}{c}-28,48 \\
(-10,45 ; 67,44) \\
\end{array}$ & 0,1402 \\
\hline F33 & $\begin{array}{l}\mathrm{A} \\
\mathrm{B}\end{array}$ & $\begin{array}{c}9,03 \\
(-71,46 ; 89,52)\end{array}$ & 0,8110 \\
\hline F34 & $\begin{array}{l}\text { A } \\
\text { B }\end{array}$ & $\begin{array}{c}1,70 \\
(-44,55 ; 47,96)\end{array}$ & 0,9374 \\
\hline F35 & $\begin{array}{l}\mathrm{A} \\
\mathrm{B}\end{array}$ & $\begin{array}{c}-31,82 \\
(-106,26 ; 48,62)\end{array}$ & 0,4245 \\
\hline F36 & $\begin{array}{l}\mathrm{A} \\
\mathrm{B}\end{array}$ & $\begin{array}{c}35,38 \\
(-52,3 ; 123,49)\end{array}$ & 0,3987 \\
\hline F37 & $\begin{array}{l}\mathrm{A} \\
\mathrm{B}\end{array}$ & $\begin{array}{c}-5,84 \\
(-71,12 ; 59,44)\end{array}$ & 0,8485 \\
\hline F38 & $\begin{array}{l}\mathrm{A} \\
\mathrm{B}\end{array}$ & $\begin{array}{c}35,03 \\
(-23,11 ; 93,18)\end{array}$ & 0,2105 \\
\hline F39 & $\begin{array}{l}\mathrm{A} \\
\mathrm{B}\end{array}$ & $\begin{array}{c}47,75 \\
(-23,67 ; 119,17)\end{array}$ & 0,1701 \\
\hline F40 & $\begin{array}{l}\mathrm{A} \\
\mathrm{B}\end{array}$ & $\begin{array}{c}9,67 \\
(-84,14 ; 103,48)\end{array}$ & 0,8205 \\
\hline F41 & $\begin{array}{l}\text { A } \\
\mathrm{B}\end{array}$ & $\begin{array}{c}16,77 \\
(-47,31 ; 80,85)\end{array}$ & 0,5747 \\
\hline F42 & $\begin{array}{l}\mathrm{A} \\
\mathrm{B}\end{array}$ & $\begin{array}{c}-25,96 \\
(-128,12 ; 76,22)\end{array}$ & 0,5900 \\
\hline F43 & $\begin{array}{l}\mathrm{A} \\
\mathrm{B}\end{array}$ & $\begin{array}{c}9,04 \\
(-86,08 ; 104,16)\end{array}$ & 0,8387 \\
\hline F44 & $\begin{array}{l}\text { A } \\
\mathrm{B}\end{array}$ & $\begin{array}{c}43,31 \\
(-34,82 ; 121,43)\end{array}$ & 0,2504 \\
\hline F45 & $\begin{array}{l}\mathrm{A} \\
\mathrm{B}\end{array}$ & $\begin{array}{c}44,67 \\
(-12,85 ; 102,19)\end{array}$ & 0,1153 \\
\hline F46 & $\begin{array}{l}\text { A } \\
\text { B }\end{array}$ & $\begin{array}{c}-6,47 \\
(-72,83 ; 59,88)\end{array}$ & 0,8351 \\
\hline F47 & $\begin{array}{l}\mathrm{A} \\
\mathrm{B}\end{array}$ & $\begin{array}{c}46,14 \\
(-21,35 ; 113,64)\end{array}$ & 0,1613 \\
\hline F48 & $\begin{array}{l}\text { A } \\
\text { B }\end{array}$ & $\begin{array}{c}32,72 \\
(-68,43 ; 133,88)\end{array}$ & 0,4915 \\
\hline F49 & $\begin{array}{l}\mathrm{A} \\
\mathrm{B}\end{array}$ & $\begin{array}{c}37,47 \\
(-30,60 ; 105,53)\end{array}$ & 0,2535 \\
\hline F50 & $\begin{array}{l}\mathrm{A} \\
\mathrm{B}\end{array}$ & $\begin{array}{c}-0,35 \\
(-63,91 ; 64,62)\end{array}$ & 0,9906 \\
\hline
\end{tabular}

Fonte: Angelo (2016, p. 99-101) 
Salientamos que a análise por falante tem a finalidade de observar se há algum informante desviante. Ela leva em consideração as diferenças de interpretação, mas não de estrutura (B vs. C) nem de sentença (1 a 9), o que pode mascarar os resultados. Como podemos observar na Tabela 3, não houve casos de significância estatística entre as leituras A ou B. Isso significa que, estatisticamente, nenhum dos nossos falantes pode ser considerado desviante e que a variabilidade nas produções deve ser interpretada como este fenômeno podendo ser considerado opcional. ${ }^{10}$

\section{Discussão} em 3.2.

Direcionamos nossa discussão com base nas predições elencadas

\subsection{Diferença de alongamento por diferença de aposição}

Dados os resultados de Angelo e Santos (2012, 2015), esperávamos que pelo menos uma tendência à produção de alongamento ocorresse para as sentenças de aposição não local em comparação às sentenças de aposição local. Para investigar essa questão, a predição para a hipótese nula que se estabelece é que sentenças com aposição não local e local teriam a mesma duração no trecho medido. Para verificar nossa hipótese nula precisamos analisar se o valor de A por estrutura é significativo em direção ao alongamento comparando com B. ${ }^{11}$

A Tabela 1 nos mostrou que, tanto no teste para médias quanto no teste para medianas, encontramos diferenças significativas em todas as comparações de estruturas não local e local. Em todos os casos, as aposições não locais foram significativamente mais longas, negando nossa hipótese nula em que não haveria diferenças entre as leituras.

\footnotetext{
${ }^{10}$ Uma explicação alternativa para esses resultados próximos pode ser o fato de só haver 14 sentenças em cada variável (falante) - ou seja, 7 versões A versus 7 versões $\mathrm{B}$, o que é um valor considerado baixo estatisticamente. Por isso o cálculo a ser mais enfaticamente considerado para os resultados e análise são os do tipo de sentença e estrutura $(n=30)$, apresentados anteriormente, pois o falante é apenas nossa variável de observação.

${ }^{11}$ Consideraremos aqui a comparação com as estruturas B como mais relevantes para verificar a hipótese nula, já que a única estrutura possível era de adjunção.
} 
Além dos resultados por estrutura, os resultados por sentença revelaram diferenças parecidas. A Tabela 2 mostrou que, com exceção da mediana da S3 (maior em B), tanto as médias quanto as medianas de todas as sentenças A foram maiores que suas versões B. Observamos que cinco das nove sentenças (S1, S4, S5, S6 e S9) tiveram as versões A significativamente mais longas que $\mathrm{B}$, negando, novamente a hipótese nula 1.

A negação dessa hipótese nula, então, confirma a existência de alongamento em PB em fronteira de frases fonológicas, o que contraria os achados de Santos e Leal (2008) para sentenças não ambíguas, assim como Angelo e Santos $(2012,2015)$ para sentenças ambíguas. Em ambas as pesquisas, as autoras não encontraram resultados significativos para a existência de alongamento em fronteira de frases fonológicas no PB.

No caso de Santos e Leal (2008), ressaltamos que, apesar de resultados diferentes, as autoras não investigaram sentenças ambíguas e sugeriram que talvez os falantes do português façam uso da duração para a desambiguação de sentenças. Em suma, encontramos exatamente o que foi sugerido por elas: que o processo se dá apenas em caso de ambiguidade (quando então o falante lança mão dessa pista para marcar na prosódia a interpretação desejada).

Angelo e Santos já haviam encontrado uma tendência ao alongamento, embora não estatisticamente significativa, e sugeriram que fosse feito um comparativo com os falantes lendo ambas as versões da ambiguidade. De fato, a leitura de ambas as versões se mostrou importante, pois aqui, em um mesmo teste, com os mesmos parâmetros, os resultados foram significativos para o alongamento.

Um outro resultado importante desse trabalho é a análise por tipo de estrutura sintática e prosódica. Angelo e Santos não distinguiram, em sua análise, sentenças com aposição por adjunto de sentenças por aposição por small clause. De fato, a detecção desses dois tipos de estruturas só ocorreu depois de o teste ter sido rodado, e, por isso, ocorre o desbalanceamento na quantidade de sentenças aqui apresentado.

Tendo então em conta apenas as sentenças A vs. B, com evidentes estruturas sintáticas e mapeamento prosódicos diferentes, nossos resultados são comprovações de que o alongamento nessas sentenças obedece às fronteiras dos domínios prosódicos (cf. NESPOR; VOGEL, 1986, p. 21-31). A significância nos resultados decorrentes das diferentes leituras é consequência do diferente mapeamento prosódico que as leituras de aposição não local e local por adjunção têm. 


\subsection{A opcionalidade do processo}

A partir de Angelo e Santos (2012, 2015), nossa predição era de que a realização do alongamento é um processo opcional dos falantes para marcar a interpretação não local. Por consequência, a hipótese nula prediz que o alongamento deve ocorrer em toda produção não local. Uma vez encontrado alongamento em PB, para saber se se trata de um processo opcional ou obrigatório, precisamos verificar se ele sempre ocorre em nossos dados por falante. Para garantir que a estrutura prosódica das sentenças com aposição local por small clause não afetasse os resultados, excluímos as sentenças S8 e S9 da análise. Em primeiro lugar, ressaltamos que nenhum falante desviou do padrão. No entanto, com a redução de sentenças, o número de variáveis ficou reduzido para 14 medidas por falantes e, quanto menor as variáveis, menor a chance de significância estatística. Em todo caso, pudemos afirmar que nenhum falante é desviante, sendo possível, então, seguir a análise com todos os dados disponíveis.

Sabendo, portanto, que, mesmo que as sentenças A sejam sempre mais longas na análise descritiva por falante (cf. ANGELO, 2016), como nem sempre esse alongamento é significativo, negamos nossa predição para a hipótese nula 2 (em que haveria alongamento em todos os casos). Com isso, podemos concluir que o alongamento é um processo opcional em $\mathrm{PB}$, pois se não fosse, teria sido realizado por todos os falantes em todos os contextos. Desse modo, confirmamos as sugestões de Angelo e Santos (2012, 2015) e Santos e Leal (2008). As primeiras autoras sugeriram que o alongamento pudesse ser opcional e perceberam a necessidade de testes com amostras pareadas para verificar essa possibilidade; já as segundas autoras não encontraram alongamento, mas sugeriram que ele pudesse ser realizado em contextos ambíguos, como um processo opcional. Levando em conta os resultados anteriores e os aqui apresentados, sugerimos que a ambiguidade seja justamente o gatilho necessário para que o falante lance mão do processo com mais frequência.

Por fim, ressaltamos que o fato de não haver alongamento significativo em todas as sentenças (e não só para todos os falantes) também nega a predição da hipótese nula para a opcionalidade do processo. Baseamos essa afirmação nos resultados por falante para discutir essa predição, pois, na análise por sentença, precisaríamos primeiramente entender se não seria o caso, também, de haver alguma 
divergência pragmática/sintática com as sentenças em que o alongamento não foi significativo, o que será discutido na Seção 7.

\subsection{Os casos de small clause}

Como mostramos nos Métodos, só percebemos que as sentenças do experimento com leitura de aposição local variavam - quanto a possibilitarem ou não mais de um tipo de estrutura - depois de rodado o teste. Assim, observamos aqui se esse último tipo de estrutura apresentaria um comportamento igual ou diferente daquele das estruturas locais por adjunção.

Na Tabela 1 vimos que o alongamento se confirmou estatisticamente em aposições não locais A, considerando a comparação entre A vs. B. Há, então, três situações possíveis para os resultados de C:

A) Não haver diferença significativa entre A e C: isso nos levaria a concluir que a estrutura escolhida pelos falantes na interpretação local de S8 e S9 foi a de small clause, pois a duração seria similar a A, a qual foi alongada em comparação a B por haver fronteira entre as frases fonológicas;

B) C ser significativamente maior que A: sugeriria um bloqueio da reestruturação e, interessantemente, indicaria a possibilidade de, em $\mathrm{C}$, o processo de alongamento ser obrigatório, pois, se há alongamento em A vs. $\mathrm{B}$, e C foi ainda mais longa, este deve ser um contexto mais propício ao alongamento pelo falante.

C) C ser significativamente menor que A: essa situação não nos daria muitas pistas sobre o que acontece com $\mathrm{C}$, pois as sentenças em C podem ter estrutura de small clause, mas também podem ser estruturas de adjunção. No caso de $\mathrm{C}$ ser menor que $\mathrm{A}$, delineiamse três possíveis respostas: (i) não há distinção na produção entre B e C; (ii) o informante preferiu a estrutura de adjunção; (iii) o alongamento, sendo opcional, não foi aplicado.

A Tabela 1 mostrou que, estatisticamente, ambas aposições locais (B e C) foram mais curtas que $\mathrm{A}$, levando-nos então à opção $\mathrm{C}$ acima A é mais longa que $\mathrm{C}$. Tal resultado deixa em aberto, em princípio, as 3 possibilidades de respostas para esse achado. Porém, observe que o p-valor de A vs. C não é tão baixo quanto o de A vs. B (p-valor de A vs. B =0,001 
(média e mediana); e p-valor de A vs. C=0,042 (média) e 0,019 (mediana)), indicando que pode haver algum tipo de diferença nessas estruturas. Essa diferença entre os resultados de $\mathrm{B}$ e $\mathrm{C}$ nos leva a crer que a resposta para A pode ser significativamente maior que $\mathrm{C}$ porque as sentenças $\mathrm{C}$ são na realidade ambíguas quanto a serem de adjunção ou small clause. Pode ter sido também o caso de algumas produções terem sido produções de uma estrutura do primeiro tipo, enquanto algumas outras estruturas, do segundo tipo. Uma maneira de se investigar se é o caso seria aplicar um teste entre sentenças em que só fossem possíveis estruturas de aposição não local vs. estruturas de aposição local por small clause. Em outras palavras, sentenças que não possibilitassem também a estruturação de sentenças com aposição local por adjunto. Infelizmente, o tipo de estrutura testado não torna possível essa contraposição. No tipo de estrutura de nosso teste, toda sentença que possibilita a estrutura de aposição local por small clause possibilita também a estrutura de aposição local por adjunção.

Não podemos esquecer, também, que há apenas duas sentenças nesse padrão, o que é considerado um número pequeno estatisticamente; assim, os resultados não são conclusivos, mas sugerem um comportamento diferente para essas sentenças, que precisa ser mais bem investigado.

Na comparação por sentenças (cf. Tabela 2), das sete sentenças que possibilitam apenas adjunção, quatro delas apresentaram diferença significativa entre A e B. Nas duas sentenças que possibilitam também small clause, uma delas não apresentou diferença entre as versões não local e local. Embora não possamos afirmar que os resultados por sentença negaram a predição da hipótese nula, os resultados por estrutura o fizeram. Ou seja, os resultados de produção, ainda que somente com dois tipos de sentenças que possibilitam small clause, demonstraram uma tendência a um comportamento um pouco diferente.

Vale ainda ressaltar que, apesar de termos utilizado como base as sentenças de Magalhães e Maia (2006), o objetivo dos autores na análise de sentenças ambíguas era encontrar indícios prosódicos de desambiguação na leitura silenciosa partindo do pressuposto de que fazemos uso de uma prosódia implícita que se comporta similarmente à prosódia explícita, auxiliando nossas interpretações no parsing (FODOR, 2002). Embora algumas pistas tenham sido encontradas, o objetivo dos autores não era verificar a existência de alongamento em fronteiras prosódicas. Nossos resultados nos levam a perguntar se os resultados de Magalhães e Maia também não podem ter sido influenciados por 
sentenças que possibilitavam small clause, pois, assim como em Angelo e Santos $(2012,2015)$, os autores não analisaram separadamente essas sentenças. Em Magalhães e Maia havia quatro sentenças com essa possibilidade: "A mãe encontrou a filha irritada", "O bandido reconheceu o cúmplice agonizante", "O réu encontrou o advogado nervoso", "O cão pegou o coelho faminto", mas as duas primeiras estavam entre as consideradas pragmaticamente ruins por seus informantes.

Em suma, dada a diferença entre o comportamento de $\mathrm{B}$ e $\mathrm{C}$, é possível que os falantes tenham alternado entre produzir estruturas de adjunção e de small clause nas versões $C$, mas há que se aplicar um novo teste para comparar estruturas em que só um dos tipos é possível e em maior quantidade.

\section{O que pode estar ocorrendo com as sentenças que fugiram do padrão encontrado no experimento?}

Tendo em vista os resultados encontrados, apesar da opcionalidade do processo, há que se perguntar o porquê de não haver alongamento significativo em todas as sentenças.

$\mathrm{Na}$ seção 4.2, conduzimos resultados sentença a sentença para observar se não haveria sentenças específicas que pudessem estar afetando os resultados, fosse por razões sintáticas (caso das estruturas small clause), fosse por razões pragmáticas. Contávamos com $n=30$ falantes para cada variável analisada (sentenças), considerado um número estatisticamente suficiente.

Como vimos, cinco sentenças foram produzidas com as versões não-locais significativamente mais longas que as versões locais (tanto na comparação de médias quanto na comparação de medianas). No entanto, as sentenças S2, S3 e S8 não apresentaram resultados significativos em nenhum dos testes. A sentença S7 foi significativa apenas no teste de Wilcoxon e, ainda assim, com um $\mathrm{p}$-valor $=0,008$, mais alto que as outras (em torno de 0,001, cf. Tabela 2). A seguir, repetimos essas sentenças.

S2. A babá ninou a menina chorando.

S3. O aluno consultou o monitor cismado.

S7. A mãe procurou a filha magoada.

S8. A mãe encontrou a filha suada. 
Como se pode observar, três das sentenças aceitam apenas leitura local por adjunto (S2, S3, S4), e uma sentença é ambígua entre adjunto e predicativo (S8). Assim, não é o caso de afirmar que o verbo da sentença estivesse influenciando os resultados - até porque outras sentenças com os mesmos tipos de leitura apresentaram significância.

Interessantemente, as quatro sentenças apresentam atributos deverbais: 'chorando', 'cismado' 'magoada' e 'suada' (derivados dos verbos 'chorar', 'cismar', 'magoar' e 'suar', respectivamente). Nas sentenças em que a significância ocorreu, os atributos eram: 'feliz', 'sonolento', 'furioso', 'sozinho' e 'nervoso', todos não verbais.

Segundo Hornstein, Nunes e Grohmann (2005), a computação sintática se dá fase a fase, sendo a construção do CP uma delas, antecedente ao spell-out:

Computational options (merger or movement, for instance) are compared within a single phase. This approach raises several interesting conceptual questions. Note, for instance, the radical derivational nature of computations under this view. Not only are syntactic objects built in a step-by-step fashion, but the interfaces are fed with information as the derivation proceeds. This raises the possibility that as the derivation proceeds, the interfaces access syntactic computations directly, in a dynamic fashion, without the mediation of LF or PF. [...] Another question that arises in this approach is why exactly VPs and CPs should be phases and, more generally, how many kinds of phases there are. (HORNSTEIN; NUNES; GROHMANN, 2005, p. 350-351).

Assumindo que o CP é uma fase, Ximenes e Nunes (2009) contrapõem sentenças como as apresentadas a seguir.

(11) A hipótese de os meninos terem viajado é implausível.

(12) A hipótese dos meninos terem viajado é implausível.

(13) *A hipótese de os meninos é implausível.

(14) A hipótese dos meninos é implausível.

As sentenças (11) e (12) contêm um verbo no infinitivo flexionado ('terem'), e os autores mostram que é opcional a utilização da não 
contração da preposição com o artigo para os falantes de PB (os autores partem do princípio de que a forma contraída é a canônica). Porém, na sentença (13), sem a presença desse verbo, vemos que a contração é obrigatória, devendo ser produzida como em (14). Ximenes e Nunes argumentam que isso ocorre devido a uma fronteira de CP vazio. Para os autores, a preposição e o sujeito no infinitivo em (11) são adjacentes, como mostrado a seguir, em (15), que explica por que a opção canônica é a contração 'de', pois carrega a marca de um CP vazio, que pode se realizar quando o infinitivo flexionado está presente. Porém, na ausência do verbo, não há um $\mathrm{CP}$, então apenas a forma canônica (contraída) pode ser usada. Em (15) as formas contraída e não contraída podem ser utilizadas, pois o 'de' introduz um C de CP. Já em (16), não há CP, então a contração é obrigatória.

(15) [[a hipótese $\left[_{\mathrm{CP}}\right.$ de [os meninos terem viajado]]]

(16) [[a hipótese $\left[_{\mathrm{PP}}\right.$ dos meninos $\left.]\right]$

Em suma, os autores sugerem que CP é interpretado pela fonologia, bloqueando a aplicação de um processo fonológico. Em outras palavras, a contração é bloqueada quando os segmentos estão em duas sentenças.

Como vimos, os atributos das sentenças de nosso teste que não apresentaram significância são todos deverbais. Seguindo a mesma linha de Ximenes e Nunes, sugerimos, então, a possibilidade de que os falantes tenham introduzido um CP antes dos atributos. Rizzi (2004) propõe que $\mathrm{C}$ (de CP) introduz um novo constituinte prosódico, como se fosse uma nova sentença. Se esse determinado constituinte sintático inicia uma nova sentença prosodicamente, isso significa que inicia uma nova frase entoacional (Intonational Phrase). Em sendo uma nova sentença, não há como haver reestruturação das frases fonológicas que o formam com as frases fonológicas de uma outra frase entoacional. Essa fronteira sintática impediria, então, a reestruturação na fonologia, assim como possibilitou a não contração nos dados de Ximenes e Nunes (2009).

Se estivermos no caminho certo, é então interessante, em uma análise futura, rodar um teste com adjetivos que são pares mínimos (verbais e não verbais), como, por exemplo, 'gelado' vs. 'frio', vs. 'quente', 'entristecido' vs. 'triste', em sentenças como 'A mãe a encontrou 
entristecida' vs. 'A mãe a encontrou triste'. ${ }^{12}$ A proposta é que, nos casos de deverbais, não tenha havido diferença entre as produções de $\mathrm{A}$ e $\mathrm{B} / \mathrm{C}$, pois esse $\mathrm{CP}$ impediria a reestruturação das frases fonológicas na interpretação local (note-se que, embora não explícito no algoritmo de Nespor e Vogel, para a reestruturação ocorrer, os domínios prosódicos devem estar dentro de um domínio prosódico superior. Se C introduz uma nova sentença, então não há como reestruturar o nome e o atributo, pois pertenceriam a sentenças diferentes.

\section{Considerações finais}

A presente pesquisa teve o objetivo de apresentar uma reanálise do processo de alongamento em fronteira de frase fonológica em contexto de desambiguação de sentenças do tipo SN1-V-SN2-Atributo, buscando trazer mais luzes sobre a questão da interação entre os componentes gramaticais (LIGHTFOOT, 1976; CHOMSKY; LASNIK, 1978; JAEGGLI, 1980). Constatamos que essa interação se dá indiretamente, ou seja, há especificamente na Fonologia um componente interpretativo que mapeia informações de outros componentes (no caso, a Sintaxe) em níveis e domínios fonológicos (SELKIRK, 1984; NESPOR; VOGEL, 1986). Com base nessa proposta, a pesquisa teve como fundamento estudos que vêm mostrando que as pessoas produzem pistas fonológicas para acessar a estrutura sintática das sentenças (SANTOS, 2003; MAGALHÃES; MAIA, 2006, 2007; GREGOLIM, 2008).

Existe na literatura uma discussão a respeito da realização fonética dos segmentos em fronteiras prosódicas em diferentes línguas. Constatouse, por exemplo, que há alongamento na produção de segmentos em fronteiras iniciais (cf. OLLER, 1973) ou finais (cf. FOUGERON; KEATING, 1997; KLATT, 1976; OLLER, 1973; WIGHTMAN et al., 1992) de domínios prosódicos e que efeitos como esse variam conforme os níveis prosódicos em que estão inseridos tornem-se mais altos.

Há três trabalhos principais em pauta que nortearam as predições deste artigo. Primeiramente, Santos e Leal (2008) observaram a não existência de alongamento de sílabas nos domínios prosódicos do português brasileiro a não ser no nível mais alto, da frase entoacional (I)

\footnotetext{
${ }^{12}$ Agradecemos aos Doutores Jairo Nunes e Marcelo Ferreira Barra, do Departamento de Linguística da FFLCH-USP, pelas discussões a respeito dessas sentenças.
} 
(cf. NESPOR; VOGEL, 1986), mas levantaram a questão de o falante realizar ou não esse efeito quando necessitasse desambiguar uma sentença. Em segundo lugar, Magalhães e Maia (2006), em um estudo a respeito da leitura silenciosa de sentenças sintaticamente ambíguas do tipo SN1Verbo-SN2-Atributo, encontraram, entre outros efeitos, um alongamento na sílaba tônica do atributo. Por fim, Angelo e Santos (2012, 2015), com base nos dois trabalhos acima citados, observaram se havia alongamento em algumas sentenças extraídas e/ou modificadas de Magalhães e Maia, mas em contexto em que poderia (ou não) haver reestruturação fonológica, esperando que houvesse maior duração nas aposições não locais. As autoras não encontraram alongamento significativo, mas sempre que ele era realizado, era em favor da aposição não local.

Buscamos com esta pesquisa, então, trazer contribuições para esses trabalhos; mais especificamente, analisar o comportamento de informantes na produção de sentenças ambíguas e, assim, buscar evidências de que o alongamento, quando realizado, seria devido a uma fronteira prosódica existente. Para isso, a metodologia utilizada contou com as mesmas nove sentenças de Angelo e Santos, gravadas com 30 informantes, aplicando o mesmo método, mas lendo ambas as versões da ambiguidade, de forma a tornar o corpus de produção ainda mais robusto, e obter resultados estatísticos mais seguros. Optou-se, também, por observar separadamente duas das sentenças por poderem ser sintaticamente estruturadas como small clauses na interpretação local.

As sentenças testadas eram ambíguas quanto a terem estrutura de aposição não local (A), estrutura de aposição local por adjunção (B) ou permitirem duas possíveis estruturas (C): de adjunção ou small clause.

Os resultados, de forma geral, corroboraram as predições levantadas. Mais do que uma tendência, encontramos que o processo de alongamento acontece em PB em contexto de desambiguação de sentenças do tipo SN1-Verbo-SN2-Atributo: as estruturas não locais foram significativamente mais longas que as locais, e em cinco das nove sentenças a versão não local (A) foi mais longa que as locais (B) ou (C).

Além disso, observamos que o processo nem sempre é realizado pelos falantes, indicando, assim, que este se trata de um processo opcional na língua, e é favorecido em situações de necessidade de desambiguação de sentenças.

Sobre as sentenças que permitem small clause, o experimento não nos forneceu muitas pistas, tendo em vista que elas também podem ter 
sido produzidas como adjunção, mas foi suficiente para negar a hipótese de que $\mathrm{B}$ se comportaria como $\mathrm{C}$, pois embora ambas as estruturas tenham sido mais curtas que $\mathrm{A}$, em $\mathrm{C}$ essa diferença foi menor.

Uma vez que tínhamos no corpus apenas duas dessas sentenças, deixamos para trabalhos futuros a investigação do que acontece com essas estruturas, em um experimento que inclua mais dados de sentenças desse tipo e de sentenças que, na versão local, tenham a possibilidade apenas de serem estruturadas em small clause.

Nossos resultados também sugerem a necessidade de um trabalho que discuta o tipo de atributo das sentenças SN1-Verbo-SN2-Atributo, já que as sentenças com atributo deverbal apresentaram um resultado diferente daquelas em que o atributo não era deverbal. Nossa hipótese, neste caso, sujeita a maiores investigações, é que sentenças com atributos deverbais sejam precedidas por uma fronteira de CP. Pelas regras de mapeamento, esse tipo de fronteira inicia um novo domínio prosódico que impede a reestruturação entre o atributo e o SN2. Assim, as sentenças com aposição local por atributo deverbal também não poderiam ser reestruturadas com o verbo e teriam, como resultado, um comportamento mais próximo das sentenças com aposição não local.

\section{Agradecimentos}

Agradecemos aos participantes da banca de mestrado de Angelo (2016) e a dois pareceristas anônimos da RELIN, pelos comentários e discussão do texto, a quem eximimos de qualquer problema remanescente.

Angelo agradece o auxílio em forma de bolsa de Mestrado do Departamento de Linguística da FFLCH/USP (CAPES Proex 2013-2015). Santos agradece o auxílio do CNPq (Bolsa Produtividade 308135/2009-1).

\section{Referências}

ABOUSALH, E. F. Resolução de choques de acento no português brasileiro. 157 f. Dissertação (Mestrado em Linguística) - Instituto de Estudos Linguísticos, Universidade de Campinas, Campinas, SP, 1997.

ANGELO, M. C. Produção e percepção na desambiguação de sentenças sintaticamente ambíguas do português brasileiro através da pista prosódica de duração. 2016. 215 f. Dissertação (Mestrado) - Universidade São Paulo, São Paulo, 2016. 
ANGELO, M. C.; SANTOS, R. S. Estruturas ambíguas e pistas prosódicas. In: SEMINÁRIO INTERNACIONAL DE FONOLOGIA, 4., 2012, Porto Alegre. Anais... Porto Alegre: UFRGS, Instituto de Letras, 2012. v.1, p.30-31.

ANGELO, M. C.; SANTOS, R. S. A prosódia em sentenças sintaticamente ambíguas do Português Brasileiro: Pistas de duração. Alfa: Revista de Linguística (UNESP. Online), v. 59, p. 375-403, 2015. Doi: https://doi. org/10.1590/1981-5794-1504-7.

ANGELO, M. C.; SANTOS, R. S. Desambiguização de sentenças na interface fonologia-sintaxe: resultados de um estudo de compreensão. Relin: Revista de Estudos da Linguagem, Belo Horizonte, v. 25, n. 3, p. 1143-1182, 2017. https://doi.org/10.17851/2237-2083.25.3.1143-1182.

BYRD, D. Articulatory Vowel Lengthening and Coordination at Phrasal Junctures. Phonetica, Los Angeles, CA, v. 57, p. 3-16, 2000. Doi: https:// doi.org/10.1159/000028456.

BYRD, D.; SALTZMAN, E. Intragestural Dynamics of Multiple Phrasal Boundaries. Journal of Phonetics. New Haven, CT. v.26, p.173-199, 1998.

$\mathrm{CHO}, \mathrm{T}$. Manifestation of Prosodic Structure in Articulation: Evidence from Lip Movement Kinecatics in English. In: GOLDSTEIN, L. (Ed.). Laboratory Phonology 8: Varieties of Phonological Competence. New York: Walter De Gruyter Inc, 2006. p. 1666-1671.

CHO, T.; KEATING, P. Articulatory Strengthening at the Onset of Prosodic Domains in Korean. Journal of Phonetics, Los Angeles, CA., v. 28, p.155-190, 2001. Doi: https://doi.org/10.1006/jpho.2001.0131.

CHOMSKY, N.; LASNIK, H. A Remark on Contraction. Linguistic Inquiry, Camberra, v. 9, n. 2, p. 268-274, 1978.

FODOR, J. D. Learning to parse? Journal of Psycholinguistic Research, Springer Link, n. 27, p. 285-319, 1998.

FODOR, J. D. Prosodic Disambiguation in Silent Reading. Proceedings of North East Linguistic Society. University of Massachusetts: Amherst, MA, n. 32, p.113-132, 2002.

FOLTRAN, M. J. As construções de predicação secundária no português do Brasil: aspectos sintáticos e semânticos. São Paulo. 1999. Tese (Doutorado) - Universidade de São Paulo, 1999. 
FOLTRAN, M. J.; MIOTO, C. A favor das small clauses revistadas. Cadernos de Estudos Linguísticos, Campinas, Unicamp, v. 49, n. 1, 2007.

FONSECA, A. A. A influência de pistas prosódicas na resolução de ambiguidades sintáticas em sentenças do tipo SN1-V-SN2-Atributo no Português Brasileiro. Veredas: Revista de Estudos Linguísticos, v. 2, n. 2, p. 150-153, 2008.

FOUGERON, C. Articulatory Properties of Initial Segments in Several Prosodic Constituents in French. Journal of Phonetics, Los Angeles, v. 29, p.109-135, 2001. Doi: https://doi.org/10.1006/jpho.2000.0114

FOUGERON, C.; KEATING, P. Articulatory Strengthening at Edges of Prosodic Domains. Journal of the Acoustic Society of America, Los Angeles. v. 101, n. 6, p. 3728-3740, 1997. Doi: https://doi. org/10.1121/1.418332.

FRAZIER, L. On comprehending sentences: syntactic parsing strategies. 1979. Tese (Doutorado) - University of Connecticut, 1979. [Reproduzida por Indiana University Linguistics Club].

FROTA, S. Prosody and focusing in European Portuguese. Phonological phrasing and intonation. New York: Garland Publishing. 2000.

GRAVINA, A. P.; FERNANDES-SVARTMAN, F. Interface sintaxefonologia: desambiguação pela estrutura prosódica no português brasileiro. Alfa: Revista de Linguística, São José Rio Preto, v. 57, n. 2, p. 639-668, 2013.

GREGOLLIM, A. As categorias vazias e os processos de sândi externo em português brasileiro. São Paulo: FFLCH, USP, 2008.

GUIMARÃES, M. Unifying LCA \& prosodic phrasing in the minimalist program. In: WORKSHOP ON THEORY OF GRAMMAR: PROBLEMS AT PF AND LF INTERFACE LEVELS, 1997. Campinas: Universidade Estadual de Campinas, 1997. Oral communication.

HORNSTEIN, N.; NUNES, J.; GROHMANN, K. K. Understanding minimalism. Cambridge: Cambridge University Press, 2005. Doi: https:// doi.org/10.1017/CBO9780511840678.

JAEGGLI, O. Remarks on To Contraction. Linguistic Inquiry, Camberra, v. 11, n. 1, p. 239-245, 1980. 
KEATING, P.; CHO, T.; FOUGERON, C.; HSU, C. Domain-initial articulatory strengthening in four languages. In: LOCAL, J.; OGDEN, R.; TEMPLE, R. (Ed.). Phonetic interpretation (Papers in Laboratory Phonology 6). Cambridge: Cambridge University Press, 2003. p.143-161.

KLATT, D. Linguistics Uses of Segmental Duration in English: Acoustic and Perceptual Evidence. Journal of Acoustic Society of America, Los Angeles, v.59, p.1208-1221, 1976. Doi: https://doi.org/10.1121/1.380986.

LADD, D. R. Intonational phonology. Cambridge: CUP, 1996.

LIGHTFOOT, D. Trace Theory and Twice-moved NPs. Linguistic Inquiry, Camberra, v. 7, n. 1, p. 559-582, 1976.

LOURENÇO-GOMES, M. C.; MAIA, M.; MORAES, J. Prosódia implícita na leitura silenciosa: um estudo com orações relativas estruturalmente ambíguas. In: MAIA, M.; FINGER, I. (Ed.). Processamento da linguagem. Pelotas: Educat, 2004. p. 131-161,

MAGALHÃES, J. O.; MAIA, M. Pistas prosódicas implícitas na resolução de ambiguidades sintáticas: um caso de adjunção de atributos. Revista da ABRALIN, Florianópolis, v. 5, n. 1-2, p.143-167, 2006.

MAIA, M. Reading and listening to garden-path PP sentences in Brazilian Portuguese. International Journal of Mind, Brain \& Cognition, Bahri Publications, v. 2. n. 1-2, p. 101-113, 2011.

MIOTO C.; SILVA, M. C. F.; LOPES, R. E. V. Novo manual de sintaxe. Florianópolis: Insular, 2004.

NESPOR, M.; VOGEL, I. Prosodic Phonology. Dordrecht: Foris Publications, 1986.

OLLER, K. The Effect of Position in Utterance on Speech Segment Duration in English. Journal of Acoustic Society of America, Los Angeles, v. 54, p. 1235-1247, 1973. Doi: https://doi.org/10.1121/1.1914393.

PIERREHUMBERT, J. The phonology and phonetics of English intonation. 1980. Tese (Doutorado) - M.I.T, Massachussets, 1980.

RIZZI, L. On the Cartography of Syntactic Structures. In: RIZZI, L. (Ed.). The Structure of IP and CP, the Cartography of Syntactic Structures. New York: Oxford University Press, 2004. p. 3-15. 
SANTOS, R. S. Traces, pro and stress shift in Brazilian Portuguese. Journal of Portuguese Linguistics, Lisboa, v. 2, n. 2, p. 101-113, 2003. Doi: https://doi.org/10.5334/jpl.30.

SANTOS, R. S.; LEAL, E. G. Os domínios prosódicos e a duração de sílaba no português brasileiro. Revista da ABRALIN, Florianópolis, v. 5, n. 1, p. 143-167, 2008.

SELKIRK, E. Phonology and Syntax: The relation between sound and structure. Cambridge: MIT Press, 1984.

TABAIN, M. Effects of Prosodic Boundary on /aC/ Sequences: Articulatory Results. Journal of Acoustic Society of America, Los Angeles, v. 113, p. 2834-2849, 2003. Doi: https://doi.org/10.1121/1.1564013.

TABAIN, M.; PERRIER, P. Articulation and Acoustics of /i/ in Preboundary Position in French. Journal of Phonetics, Los Angeles, v. 33, p. 77-100, 2005. Doi: https://doi.org/10.1016/j.wocn.2004.04.003.

VIGÁRIO, M. The prosodic word in European Portuguese. Berlin: Mounton de Gruyter, 2003. Doi: https://doi.org/10.1515/9783110900927.

XIMENES, C.; NUNES, J. Preposition Contraction and Morphological Sideward Movement in Brazilian Portuguese. In: NUNES, J. (Org.). Minimalist Essays on Brazilian Portuguese Syntax. Amsterdam: John Benjamins, 2009. p. 191-214.

WIGHTMAN, C.; SHATTUCK-HUFNAGEL, S.; OSTENDORF, M.; PRICE, P. Segmental Durations in the Vicinity of Prosodic Phrase Boundaries. Journal of Acoustic Society of America, Los Angeles, n. 91, p. $1707-1717,1992$. 